\section{Insulin Allergy Treated by Low-dosage Hydrocortisone}

Brit.med. F., 1967, 3, 722

Allergy to insulin was a common problem in the early days of treating diabetes mellitus (Lawrence, 1925 ; Marble, 1959), but introduction of purified preparations has made this less likely. Allergic patients can usually be treated by desensitization or by changing the type of insulin (Marble, 1959).

Today many patients needing only small doses of insulin have been prescribed oral hypoglycaemic agents instead. However, these may be inadequate during infections or operations, or if the diabetes becomes worse, and so insulin may be given again. A secondary immune response is then apt to occur, causing local or general allergy and sometimes fatal anaphylaxis (Hanauer and Batson, 1961 ; Michel, 1963 ; Aiken, 1964). We encountered this problem in the following case and used a different method of overcoming allergy.

\section{CASE Report}

A 49-year-old housewife developed diabetes mellitus in 1960 and was given insulin zinc suspension. A few days later she developed painful red swellings at the injection sites. As her diabetes was mild insulin was stopped and tolbutamide substituted.

Five years later oral hypoglycaemic drugs failed. Isophane insulin controlled the blood-sugar level, but local allergic reactions again occurred. Soluble, globin zinc, and Actrapid insulins produced similar reactions whether injected subcutaneously or intramuscularly. After 13 days she developed a widespread urticarial rash, angioneurotic oedema, and dyspnoea. Antihistamines provided no relief, and so, as symptoms were severe and potentially dangerous, prednisone $10 \mathrm{mg}$. was given by mouth; remission occurred within one hour.

After this her diabetes was controlled by soluble insulin ( 28 i.u. morning and 32 i.u. evening) and the allergy suppressed with prednisone by mouth $10 \mathrm{mg}$. q.d.s. However, on reducing the dose of prednisone below $20 \mathrm{mg}$. daily allergic symptoms recurred. As this dose was undesirable it was decided to inject a corticosteroid drug with the insulin. Prednisolone $2 \mathrm{mg}$. failed, but hydrocortisone $10 \mathrm{mg}$. prevented both local and systemic reactions. The blood sugar level was controlled, there being no insulin resistance, and the patient improved. Within two weeks as little as $2 \mathrm{mg}$. of hydrocortisone mixed with each injection of soluble insulin was satisfactory. Less than this allowed skin reactions of increasing severity to recur and the patient used $2 \mathrm{mg}$. again of her own accord.

\section{"Railroading" in Retinal Vessels}

Brit. med. F., 1967, 3, 722-723

Among the many problems involved in the treatment of cardiac arrest is that of deciding during the period of emergency whether the brain has been damaged irreversibly and when resuscitation should be abandoned. Widely dilated pupils and stagnant cyanosis do not necessarily mean that the patient is dead. Obviously it is undesirable to continue resuscitation if the brain is dead. Treatment should be abandoned as soon as this is clearly indicated.

"Railroading" or " cattle-trucking" seen during ophthalmoscopic examination of the retina is a well-known physical sign of death in traditional medicine in Britain, though it is not well known in some other countries. This physical sign is not described in many of the standard textbooks, though a brief description is given by Smith and Simpson (1956). It may develop as late as several minutes after cessation of the heartbeat and it may be seen until the cornea clouds over.

What one observes is a fragmentation of the column of blood within the retinal vessels. The fragments or aggregates of red
A limited supply of insulin recrystallized six times was used. This, while superior to soluble insulin alone, was not entirely free of allergic properties, occasionally producing weals with induration up to $1 \mathrm{in} .(2.5 \mathrm{~cm}$.) in diameter. The mixture of soluble insulin with hydrocortisone was therefore restarted. Hydrocortisone was omitted from trial injections at approximately fortnightly intervals until after about six months soluble insulin could be used alone without adverse effect.

\section{COMMENT}

The occurrence of allergy to several different types of insulin of bovine and porcine origin suggests that the reaction is to either insulin itself or to a constant impurity. The latter seems more likely because recrystallization of insulin lowers the incidence of allergy greatly (Jorpes, 1949, 1950).

Desensitization is a lengthy and sometimes difficult procedure, whereas suppression of symptoms with corticosteroids is simple. The use of hydrocontisone, which mixes well with soluble insulin, allows less corticosteroid to be employed, with reduced risk of adverse side-effects. In this case the dose was within the range of endogenous cortisol production $16.2 \pm 5.7$ mg./24 hours (Cope, 1965). Presumably slow desensitization then occurs under corticosteroid cover. The only disadvantage is the need to mix drugs for injection.

This method is suggested (1) as an alternative in simple cases of insulin allergy, (2) when speed is important, (3) in cases resistant to the more usual methods of treatment, and (4) when recrystallized insulin is not available.

We wish to thank Dr. C. F. Hawkins for constant encouragement and for permission to publish this case, and Dr. R. A. Ellis, of the Medical Division, Boots Pure Drug Company Limited, Nottingham, for supplying the insulin recrystallized six times.

Queen Elizabeth Hospital, Birmingham 15.

ROY COCKEL, M.A., M.B., M.R.C.P. SHEILA MANN, M.B., CH.B.

REFERENCES

Aiken, J. B. (1964). Canad. med. Ass. F., 91, 660.

Cope, C. L. (1965). Adrenal Steroids and Disease, p. 160. London.

Hanauer, L., and Batson, J. M. (1961). Diabetes, 10, 105.

Jorpes, . E. (1949). Arch. intern. Med., 83, 363.

- (1950). Acta med scand., 138, Suppl. No. 239, p. 313.

Lawrence, R. D. (1925). Lancet, 1, 1125.

Marble, A. (1959). In Treatment of Diabetes Mellitus, by E. P. Joslin, H. F. Root, P. White, and A. Marble, 10th ed., p. 401. London. Michei, H. (1963). Med. Welt (Stuttg.), 1, 909.

cells move in either direction along the vessel at random and may collide with each other. This has been fancifully likened to the sequence of events that occur when a trainload of unbraked goods wagons stops. Accompanying the movement of the red cells, the diameter of the vessels alters rapidly, sometimes narrowing, sometimes dilating. The vessel itself may appear to be moving rapidly in and out of focus of the ophthalmoscope. This may be erroneously attributed to an inability to use the ophthalmoscope during the stress conditions of treating cardiac arrest by those making the examination.

What is not known is the significance of this sign in situations of cardiac arrest. The association of the time of its appearance to the known time of survival of the brain after circulatory arrest suggests that it appears at or after death of the brain rather than with cessation of the circulation. This physical sign could provide a good guide to prognosis, as shown in this case report.

\section{CASE REPORT}

A girl aged 10, a severe asthmatic, was admitted to hospital having "collapsed" approximately 15 minutes earlier during an asthmatic attack at home. 